\title{
Prevention of Diabetic Nephropathy in $\mathrm{db} / \mathrm{db}$ Mice with Glycated Albumin Antagonists
}

\section{A Novel Treatment Strategy}

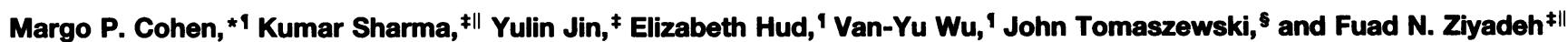
Departments of * Biochemistry, ${ }^{\ddagger}$ Medicine, and ${ }^{\S}$ Pathology, and the $"$ Penn Center for Molecular Studies of Kidney Diseases, University of Pennsylvania School of Medicine; and 'Exocell, Inc., Philadelphia, Pennsylvania 19104

\begin{abstract}
Accelerated protein glycation in diabetes has been mechanistically linked to the pathogenesis of diabetic nephropathy. Because glycated albumin induces abnormalities in cultured mesangial cells that resemble those characterizing the glomerular mesangium in diabetes, and monoclonal antibodies (A717) specific for Amadori-modified glycated albumin prevent these abnormalities, we postulated that in vivo administration of $\mathbf{A 7 1 7}$ could retard the progression of diabetic nephropathy. To test this hypothesis, diabetic $d b / d b$ mice and their nondiabetic $\mathrm{db} / \mathrm{m}$ littermates were treated with eight consecutive weekly injections of $150 \mu \mathrm{g}$ of A717 (Fab fragments) to reduce the elevated plasma glycated albumin concentration, or with irrelevant murine IgG (MIg). Relative to nondiabetics, diabetic mice (MIg treated) manifested proteinuria $(3.35 \pm 0.15$ vs $0.87 \pm 0.1 \mathrm{mg}$ albumin/mg creatinine), 3.8-fold increase in mesangial matrix fraction, and renal cortical overexpression of mRNAs encoding $\alpha 1$ (IV) collagen (2.6-fold increase) and fibronectin (3.8-fold increase). Treatment of $d b / d b$ mice with $A 717$ significantly reduced the proteinuria $(1.52 \pm 0.3 \mathrm{mg} / \mathrm{mg}$ creatinine), inhibited mesangial matrix expansion, and attenuated overexpression of matrix mRNAs. The nephropathic protective effects of A717 were independent of any change in blood glucose concentrations. Antibodies unreactive with glycated albumin did not duplicate the beneficial effects of $\mathbf{A 7 1 7}$. Thus, abrogating the biologic effects of increased glycated albumin with A717 has a salutary influence on the pathogenesis of diabetic nephropathy and has novel therapeutic potential in its management. ( $J$. Clin. Invest. 1995. 95:23382345.) Key words: mesangium • collagen type IV • fibronectin • nonenzymatic glycation • albuminuria
\end{abstract}

\section{Introduction}

The direct relationship between hyperglycemia and increased nonenzymatic glycation, the condensation reaction between free

Address correspondence to Fuad N. Ziyadeh, Renal-Electrolyte \& Hypertension Division, 700 Clinical Research Building, University of Pennsylvania, 422 Curie Boulevard, Philadelphia, PA 19104-6144. Phone: 215-662-3603; FAX: 215-898-0189.

Received for publication 19 September 1994 and in revised form 10 January 1995.

J. Clin. Invest.

(C) The American Society for Clinical Investigation, Inc.

$0021-9738 / 95 / 05 / 2338 / 08 \quad \$ 2.00$

Volume 95, May 1995, 2338-2345 glucose and reactive protein amino groups that is accelerated in diabetes (1-9), has implicated excess protein glycation as a mechanistic link between hyperglycemia and the pathogenesis of diabetic nephropathy. This postulate has been strengthened with experimental evidence demonstrating that glycated serum proteins adversely affect renal glomerular capillary function, structure, and metabolism (10-13). In previous studies, we have shown that human sera containing diabetic concentrations of glycated albumin inhibit the replication of murine mesangial cells in culture and stimulate the production and gene expression of type IV collagen, the principal constituent of the expanded extracellular matrix observed in the diabetic renal glomerulus (14-18). The glycated serum-induced effects on mesangial cell replication and collagen IV synthesis are duplicated by supplementation of culture media with purified glycated albumin, and they are prevented by monoclonal antibodies (A717) that specifically react with Amadori-modified albumin (14, 19, 20). In light of these findings, we reasoned that, if the consequences of increased glycated albumin in diabetes on mesangial cell biology are similar in vivo, abrogating its influence by lowering plasma glycated albumin and/or neutralizing its biologic activity could have a salutary influence on the development of glomerular pathology in diabetes.

In initial experiments to test this hypothesis, we determined the feasibility of administering A717 monoclonal antibodies to diabetic animals (21). We chose the $d b / d b$ mouse as the experimental model because glomerular mesangial expansion resembling that found in human diabetes has been documented in this genetic model of diabetes (22-24). The main purposes of this pilot study were to establish that A717 reacted with rodent glycated albumin, to determine a treatment regimen that could lower plasma glycated albumin, and to examine the effect of the regimen on proteinuria. We found that A717, a murine monoclonal antibody raised against Amadori-modified human albumin, recognizes glycated murine albumin. Plasma glycated albumin concentrations were elevated two- to threefold in $\mathrm{db} /$ $d b$ mice compared with their nondiabetic $d b / m$ littermates, and they declined after A717 administration. Weekly injections of A717 (Fab fragments) for 7 wk to diabetic animals reduced urine protein excretion and appeared to attenuate mesangial prominence, assessed by visual inspection, relative to untreated diabetic controls (21). These encouraging results prompted the present study, in which the effect of treatment with A717 on abnormalities in glomerular structure, function, and cell biology characteristic of diabetic renal disease were rigorously analyzed. The main purposes of the present study were to conduct detailed glomerular morphometric analysis and, through analysis of type IV collagen and fibronectin mRNA levels in the renal cortex, to address mechanisms by which antiglycated albumin therapy with A717 affects matrix accumulation. Urine albumin excre- 
tion was also examined. Specifically, we show that the mRNAs encoding $\alpha 1$ (IV) collagen and fibronectin are significantly increased in the kidney cortex of $d b / d b$ mice, and that treatment with Fab fragments of A717 markedly attenuates this increase. Histomorphometric measurements demonstrate that A717 therapy also prevents the increase in glomerular mesangial matrix. Additionally, we show that albuminuria is reduced by A717 treatment and document the inability of antibodies unreactive with glycated albumin to duplicate the beneficial effects of A717.

\section{Methods}

Experimental animals. Diabetic $d b / d b$ mice and their nondiabetic $d b /$ $m$ littermates were each divided into two groups of six animals per group. One group in each set was treated with the A717 monoclonal antibody (mAb A717), and the other group received irrelevant murine IgG (MIg). ${ }^{1}$ Antibody was administered intraperitoneally (150 $\mu \mathrm{g}$ per mouse) every week for 8 consecutive wk, commencing when mice were $8-10$ wk old. The $d b / d b$ mice were designated diabetic by the vendor (Jackson ImmunoResearch Laboratories, Inc., Bar Harbor, ME) on the basis of appearance of obesity at $\sim 5 \mathrm{wk}$ of age and were hyperglycemic when tested after arrival in our laboratory (mean blood glucose concentration $17.1 \pm 2.3 \mathrm{mM}$ in $d b / d b$ vs $4.5 \pm 0.45 \mathrm{mM}$ in $d b / m$ ). The antibody treatment regime was selected on the basis of previous experiments that showed that the elevated plasma glycated albumin concentrations in $d b / d b$ mice were significantly reduced $48 \mathrm{~h}$ after intraperitoneal administration of $100 \mu \mathrm{g}$ of Fab fragments of the mAb A717 (21), and also took into account stoichiometric relationships, the circulating halflife of albumin, and other studies using chronic administration of monoclonal antibodies (25-31). Mouse plasma volume is $\sim 1.2 \mathrm{ml}$ with an albumin concentration of $15 \mathrm{mg} / \mathrm{ml}$, of which $\sim 2 \%(360 \mu \mathrm{g})$ is glycated in nondiabetic, normoglycemic animals. Glycated albumin is increased 1.5-2-fold in diabetes $(7,26,27,32)$. On a stoichiometric basis, $150 \mu \mathrm{g}$ antibody Fab fragments (mol wt $\sim 50 \mathrm{kD}$ ) would neutralize $\sim 200 \mu \mathrm{g}$ of glycated albumin ( $\mathrm{mol} \mathrm{wt} \sim 66.5 \mathrm{kD}$ ). We hoped to augment efficacy with this dose, which was higher than that used in our previous study. Albumin has a circulating half-life of 3-5 d in the mouse, but glycation may slow clearance of plasma proteins, prompting the weekly injection schedule (28-31).

Antibody preparations. A717 monoclonal antibody was harvested from ascitic fluid of mice injected with the A717 cell line and purified by affinity chromatography on protein $\mathrm{G}$. Fab fragments were prepared with papain digestion and separated from $\mathrm{Fc}$ fragments and undigested IgG with protein A affinity chromatography (21). Retention of combining ability of the Fab fragment with the epitope in glycated albumin was documented by ELISA $(7,21)$. Reactivity of A717, a murine monoclonal antibody of the IgG1 class that selectively recognizes Amadori-modified albumin $(7,14,19,20)$,.with the epitope in rodent glycated albumin was documented as previously described $(21,32)$. Antibody preparations were sterile filtered and administered intraperitoneally in buffered saline. Affinity-purified murine IgG, unreactive with glycated albumin or other circulating proteins, was subjected to the same procedure before injection.

Urine albumin assays. Urine albumin was determined in 24-h urine samples from each animal collected at the beginning and the conclusion of the study. Albumin concentrations were measured with a competitive ELISA in which mouse albumin in soluble phase competed with albumin immobilized onto microtiter wells ( $250 \mathrm{ng} /$ well) for binding to horse radish peroxidase-conjugated antibody against rodent albumin. After addition of standard or sample in $200 \mu \mathrm{l}$ reaction buffer and equilibration for $60 \mathrm{~min}$, horse radish peroxidase conjugate (1:4,000 dilution in 10\%

1. Abbreviation used in this paper: MIg, murine immunoglobulin.
FCS, $0.1 \mathrm{M}$ Tris, $\mathrm{pH}$ 6.8) was added and the reaction was allowed to proceed for $30 \mathrm{~min}$ at room temperature. After washing with saline containing Tween 20, substrate color developer (TM Blue) and then stopper $\left(1 \mathrm{M} \mathrm{H}_{2} \mathrm{SO}_{4}\right)$ were added, and the absorbances in the wells were read at $450 \mathrm{~nm}$. Albumin excretion was normalized to urine creatinine, measured with the creatinine color reagent (Sigma Chemical Co., St. Louis, MO).

Northern analysis. Northern blots of RNA extracted from renal cortex were hybridized with ${ }^{32} \mathrm{P}$-labeled cDNA encoding murine $\alpha 1$ (IV) collagen, fibronectin, GAPDH, or $18 \mathrm{~S}$ rRNA as previously described $(14,33)$. The snap-frozen tissue was denatured in $4 \mathrm{M}$ guanidinium thiocyanate, $25 \mathrm{mM}$ sodium citrate, $\mathrm{pH} 7.0,0.5 \%$ sarcosyl, and $0.1 \mathrm{M}$ 2-mercaptoethanol. Total RNA ( $20 \mu \mathrm{g}$ from each animal) was electrophoresed on a $1.2 \%$ agarose gel, transferred onto nylon membranes, and ultraviolet wave cross-linked, and the membrane was hybridized with labeled cDNA inserts $\left(\left[{ }^{32} \mathrm{P}\right]\right.$ deoxycytidine 5 'triphosphate $[3,000 \mathrm{Ci} /$ mmol; Amersham, Arlington Heights, IL]) using random priming (Amersham). After hybridization, blots were washed for $30 \mathrm{~min}$ in $2 \times \mathrm{SSC}$ with $0.1 \%$ SDS at $62^{\circ} \mathrm{C}$, followed by two 15 -min washes in $0.1 \times$ SSC with $0.1 \%$ SDS at $62^{\circ} \mathrm{C}$. The membranes were then autoradiographed with intensifying screens at $-70^{\circ} \mathrm{C}$ for up to $10 \mathrm{~d}$. Blots were then stripped for $2 \mathrm{~h}$ at $62^{\circ} \mathrm{C}$ with $5 \mathrm{mM}$ Tris, $0.2 \mathrm{mM}$ EDTA (pH 8.0), and $5 \%$ sodium pyrophosphate, and subsequently rehybridized with cDNA fragment-encoding ribosomal 18S RNA to account for small variations in loading and transfer. Exposed films were scanned with a laser densitometer (Hoefer Scientific Instruments, San Francisco, CA), and collagen or fibronectin mRNA levels were calculated relative to those of $18 \mathrm{~S}$.

Glomerular histology and morphometry. A portion of the renal cortex was removed when the animals were killed at the end of the study, fixed in $10 \%$ neutral buffered formalin, and embedded in paraffin. Renal sections ( $3 \mu \mathrm{m}$ thick) were stained with hematoxylin and eosin and periodic acid Schiff (PAS). For quantitation, sections were coded and read by an observer unaware of the experimental protocol applied. 1015 glomeruli were selected at random in PAS-stained sections from each animal in each experimental group. The extent of increase in mesangial matrix was determined by the presence of PAS-positive material in the mesangial region using a digital planimeter (Southern Microscope Instruments, Inc., Atlanta, GA) and factored by the glomerular tuft area.

Antibody appearance in renal cortex. To investigate whether circulating monoclonal antibody reached renal cortex, male BALB/c mice were killed 12, 24, and $48 \mathrm{~h}$ after intravenous injection of $200 \mu \mathrm{g} \mathrm{A717}$ (Fab fragments). Renal cortex was rapidly dissected from medulla, rinsed with buffered salt solution, minced, washed several times, and snap frozen. The tissue was homogenized in alkaline buffer $(100 \mathrm{mM}$ $\mathrm{NaCl}, 25 \mathrm{mM}$ imidazole, $1 \mathrm{mM}$ EDTA, $50 \mathrm{mM}$ diethylamine, $\mathrm{pH} 11.0$ ) containing $0.05 \%$ NP-40 to liberate antibody bound to glycated albumin in the parenchyma or vascular residuum. After $1 \mathrm{~h}$, the homogenates were centrifuged at $3,000 \mathrm{~g}$ for $10 \mathrm{~min}$; the supernatant was neutralized to $\mathrm{pH} 6.8$ with $1 \mathrm{M}$ acetic acid and clarified by centrifugation. Aliquots of the supernatant were analyzed for A717 monoclonal antibody by enzyme immunoassay, in which glycated albumin was immobilized onto microtiter wells ( $1 \mu \mathrm{g} /$ well $)$, and enzyme-conjugated polyclonal antibody against mouse Fab fragments was used as developer. Sample or standard (Fab fragments of affinity-purified A717) were added to the wells in reaction buffer $(100 \mathrm{mM} \mathrm{NaCl}, 25 \mathrm{mM}$ imidazole, $1 \mathrm{mM}$ EDTA, pH 6.8) and incubated for $1 \mathrm{~h}$ at room temperature. After washing and incubation for $1 \mathrm{~h}$ with the conjugated second antibody, color was developed with TM Blue substrate (Promega Corp., Madison, WI), the reaction was stopped with $1 \mathrm{M} \mathrm{H}_{2} \mathrm{SO}_{4}$, and absorbance in the wells was measured at $450 \mathrm{~nm}$ with an ELISA reader.

Statistical analysis. Data are presented as the mean \pm SEM, with $n$ representing the number of animals. Groups were compared by ANOVA, and the Wilcoxon-Mann-Whitney test was used to compare individual groups; $P$ values $<0.05$ were considered significant. 
Table I. Experimental Animal Data

\begin{tabular}{lllcc}
\hline & $d b / d b$ MIg & $d b / d b$ A717 & $d b / m$ MIg & $d b / m$ A717 \\
\hline Blood glucose (mM) & & & & \\
$\quad$ Week 2 & $26.7 \pm 2.7$ & $23.3 \pm 2.1$ & nd & nd \\
Conclusion & $22.6 \pm 0.6^{*}$ & $21.1 \pm 1.1^{*}$ & $5.8 \pm 0.6$ & $6.1 \pm 0.4$ \\
Body wt (g) & $33.8 \pm 2.7^{*}$ & $35.4 \pm 2.0^{*}$ & $28.4 \pm .75$ & $26.0 \pm 1.4$ \\
Kidney wt (g) & $0.42 \pm .03^{*}$ & $0.45 \pm .05^{*}$ & $0.35 \pm .03$ & $0.31 \pm .03$ \\
& & & & \\
\hline
\end{tabular}

$d b / d b$ diabetic mice and their nondiabetic $d b / m$ littermates received weekly intraperitoneal injections of mAb A717 or irrelevant MIg for 8 consecutive wk commencing at 9 wk of age. Results represent mean \pm SEM of six animals per group. Body and kidney weights in $d b / d b$ mice, taken at the conclusion of the study, were greater than in $d b / m$ mice. None of the $d b / d b$ mice were treated with insulin or other glucose-lowering agent, and blood glucose concentrations remained elevated throughout the study. $n d$, not determined; $* P<0.05$ compared with $d b / m$.

\section{Results}

The $d b / d b$ mouse is a model of genetic diabetes that exhibits hyperglycemia associated with obesity a few weeks after birth (Table I). It develops glomerular mesangial expansion and histologic lesions resembling those found in human diabetes (2124 ). Diabetic $d b / d b$ mice used in the present study remained hyperglycemic throughout the experimental period, and their body weights were significantly greater than nondiabetic controls (Table I). Kidney weights were also significantly greater in $d b / d b$ compared with $d b / m$ mice (Table I). Kidney to body weight ratios did not significantly differ between nondiabetic versus diabetic animals, given that the latter had greater body weights. Blood glucose concentration, body weight, and kidney weight were unaffected by monoclonal antibody therapy in diabetic or nondiabetic mice. Since A717 specifically recognizes glycated albumin and does not react with free glucose, it is not expected to influence blood glucose, metabolic status, or kidney cell enlargement directly due to hyperglycemia $(33,34)$.

Albumin excretion, the established parameter reflecting diabetic glomerular dysfunction (35), was significantly increased in $d b / d b$ compared with $d b / m$ mice at the start of the study (before injection). At the conclusion of the study, urine albumin, normalized in relation to urine creatinine to control for possible incomplete collection, remained significantly greater in $d b / d b$ controls (MIg treated) compared with $d b / m$ controls, indicating that it was not influenced by treatment with IgG not reactive with glycated albumin (Fig. 1). In contrast, treatment of $d b / d b$ mice with mAb A717 significantly lowered urine albumin (Fig. 1), confirming the beneficial influence of A717 on this manifestation of renal dysfunction in diabetes. The salutary effect of A717 on albumin excretion cannot be attributed to an untoward influence to diminish glomerular filtration since the measured creatinine clearance was not significantly reduced in $d b / d b$ mice that received $\mathrm{A} 717$ versus those that received murine IgG (not shown).

Northern blot analysis demonstrated increased levels of mRNA encoding the $\alpha 1$ chain of type IV collagen in renal cortex from $d b / d b$ mice receiving irrelevant IgG, compared with nondiabetic controls (Fig. $2 A$ ). Thus, diabetic $d b / d b$ mice manifest renal pathobiology with overexpression of renal

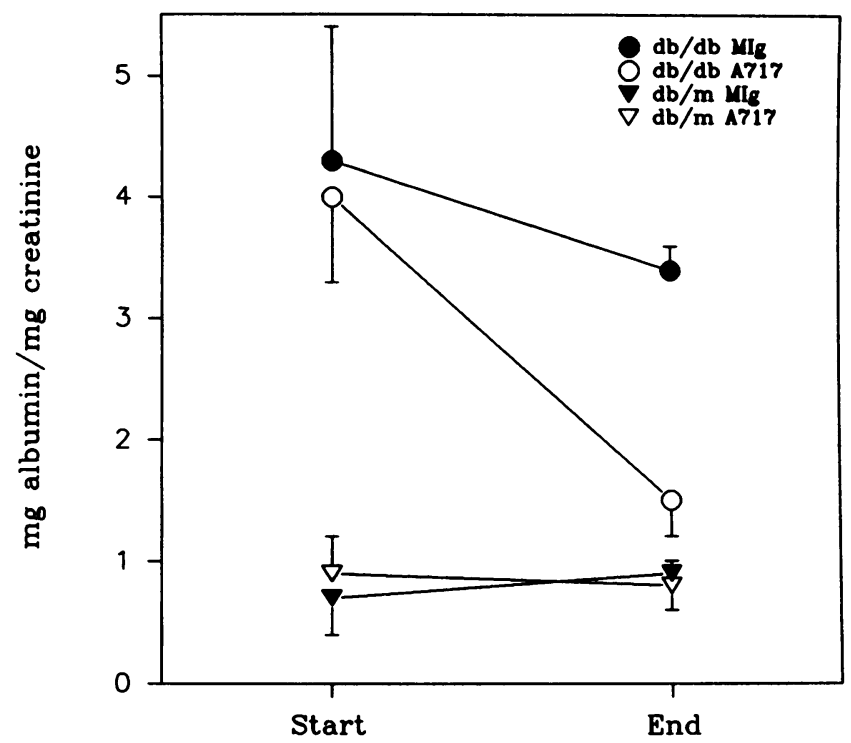

Figure 1. The prevention of albuminuria by mAb A717 treatment. Urine albumin excretion was measured in male $d b / d b$ mice and their nondiabetic $\mathrm{db} / \mathrm{m}$ littermates that were treated with affinity-purified mAb A717 or irrelevant mouse IgG (MIg). Antibody treatment was initiated when mice were $9 \mathrm{wk}$ old and maintained throughout the study (150 $\mu \mathrm{g}$ per mouse every week for $8 \mathrm{wk}$ ). At the conclusion of the study, urine albumin excretion in mAb A717-treated $d b / d b$ mice was significantly less $(P<0.05)$ than in $d b / d b$ mice receiving MIg. Results are expressed as mean \pm SEM; six animals per group.

cortical collagen IV mRNA at age 16 wk. Increased kidney type IV collagen mRNA has been found in other rodent models of genetic and acquired diabetes (36-38). Denistometric scanning of the exposed autoradiographs allowed calculation of type IV collagen mRNA levels in relation to $18 \mathrm{~S}$ rRNA levels. Relative to nondiabetic controls, the renal type IV collagen:18S rRNA ratio was 2.6-fold greater in the $d b / d b$ control mice (Fig. $2 B$ ). Treatment with mAb A717 had no effect on type IV collagen gene expression in renal cortex of nondiabetic $d b /$ $m$ mice (Fig. 2). In contrast, treatment with the mAb A717 significantly decreased the elevated type IV collagen gene expression observed in the $d b / d b$ mice; the renal type IV collagen:18S rRNA ratio in mAb A717-treated $d b / d b$ mice did not differ from the ratio in nondiabetic $\mathrm{db} / \mathrm{m}$ mice that received irrelevant IgG or A717 monoclonal antibody (Fig. 2).

The diabetic $d b / d b$ mouse also manifests overexpression of renal cortical fibronectin mRNA at age $16 \mathrm{wk}$ (Fig. $3 \mathrm{~A}$ ). Relative to nondiabetic controls, the renal fibronectin:18S rRNA ratio was 3.8-fold greater in the $d b / d b$ control mice (Fig. 3 $B$ ). Treatment with $\mathrm{mAb} A 717$ had no effect on fibronectin gene expression in renal cortex of nondiabetic $\mathrm{db} / \mathrm{m}$ mice (Fig. 3 ). In contrast, treatment with the mAb A717 significantly decreased the elevated fibronectin gene expression observed in the $d b / d b$ mice by nearly $50 \%$. It should be noted that the expression of the housekeeping gene GAPDH (relative to that of 18S rRNA) was identical in the renal cortex of $d b / d b$ mice treated with either A717 or MIg (data not shown); this finding indicates that the effect of A717 antibody on gene expression is not nonspecifically repressive.

Renal glomeruli in specimens obtained from $d b / d b$ controls 
A

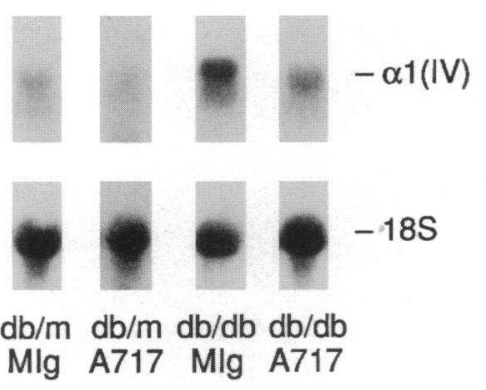

B

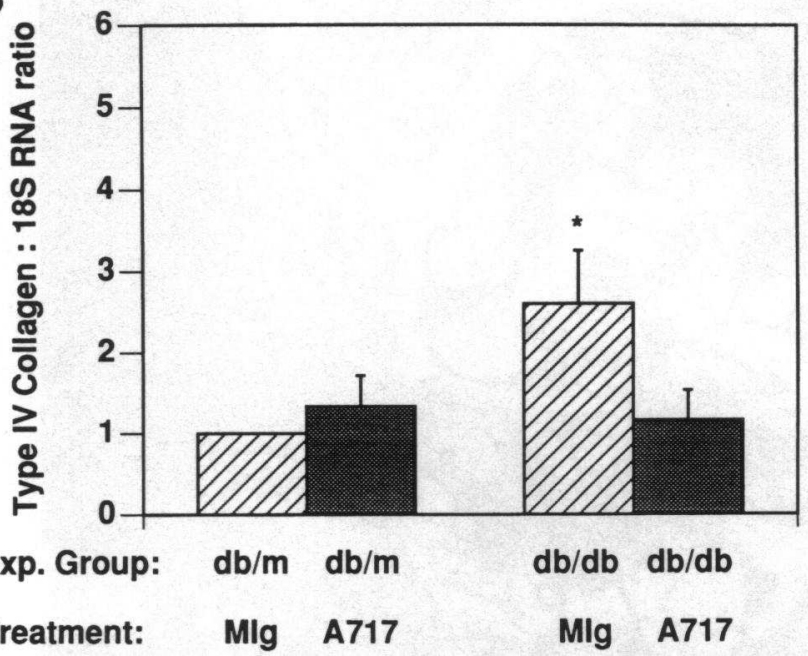

Figure 2. Prevention by mAb A717 of increased renal type IV collagen gene expression in $d b / d b$ mice. Total RNA was extracted from snapfrozen renal cortex when animals were killed at the end of the study period. $A$ depicts representative Northern blots from each group of experimental animals; $B$ shows type IV collagen mRNA levels in relation to 18S RNA levels calculated by densitometric scanning of the exposed films. Results represent mean \pm SEM of four animals in each group when the type IV:18S rRNA ratio in $\mathrm{db} / \mathrm{m}$ MIg-treated mice is assigned an arbitrary value of 1.0. Antibody treatment and animal groups as in Fig. 1. *Significantly different from $\mathrm{db} / \mathrm{m}$ and $\mathrm{db} / \mathrm{db}$ treated with $\mathrm{mAb} \mathrm{A} 717(P<0.05)$.

when the mice were killed at the conclusion of the study showed diffuse mesangial expansion, with increased mesangial matrix encroaching the normal capillary network (Fig. $4 B$ vs $4 A$ ). Glomeruli from $d b / d b$ mice treated with $\mathrm{mAb} A 717$ were visibly different and exhibited appreciably less mesangial expansion (Fig. $4 C$ ). This difference was quantitated by glomerular morphometry, determining on a grid the cross-sectional glomerular surface area and the mesangial matrix area. The fraction of total glomerular tuft cross-sectional area occupied by mesangial matrix was $0.0328 \pm 0.0026$ in nondiabetic MIg-treated $\mathrm{db} / \mathrm{m}$ mice, $0.0235 \pm 0.0015$ in $\mathrm{A} 717$-treated $\mathrm{db} / \mathrm{m}$ mice, $0.1239 \pm 0.010$ in $d b / d b$ MIg controls, and $0.0722 \pm 0.0056$ in $d b / d b$ mice treated with mAb A717. There was a 3.8-fold increase in the mesangial matrix fraction in $\mathrm{db} / \mathrm{db}$ controls relative to $\mathrm{db} / \mathrm{m}$ mice; treatment with A717 monoclonal antibody reduced the mesangial matrix fraction to $58 \%$ of that in the MIg-treated $d b / d b$ controls (Fig. $4 D$ ).

Monoclonal antibody A717 was measurable in renal cortex $12 \mathrm{~h}$ after intravenous injection of $200 \mu \mathrm{g}$ and remained detectable for at least $48 \mathrm{~h}$ after injection (Fig. 5). Antibody was not detected in extracts of renal cortex from noninjected control mice, corroborating the validity of the immunoanalytic proce-
A

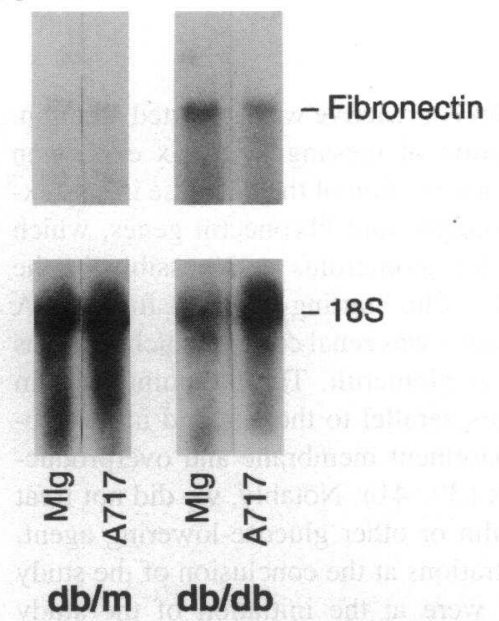

B

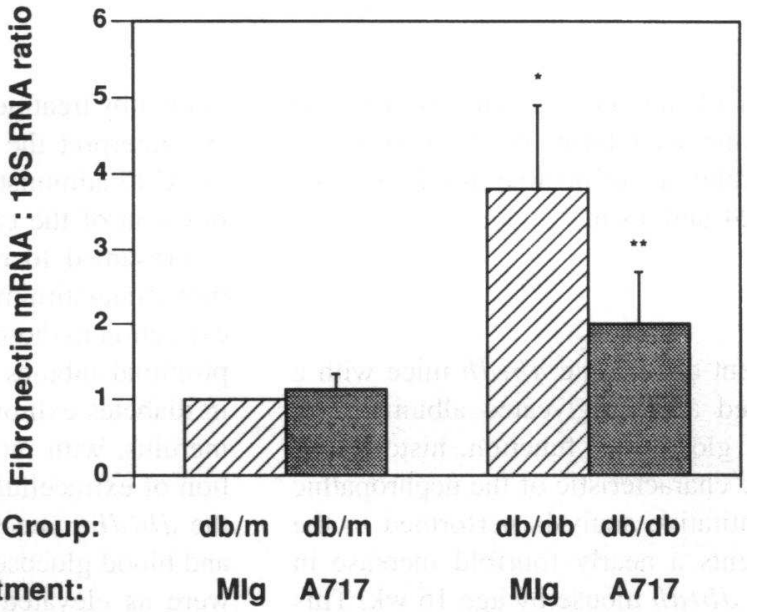

Figure 3. Attenuation by mAb A717 of increased renal fibronectin gene expression in $d b / d b$ mice. $A$ depicts representative Northern blots from each group of experimental animals; $B$ shows fibronectin mRNA levels in relation to $18 S$ rRNA levels (mean \pm SEM of six animals in each group) when the fibronectin:18S rRNA ratio in $\mathrm{db} / \mathrm{m}$ MIg-treated mice is assigned an arbitrary value of 1.0 . Antibody treatment and animal groups as in Fig. 1. *Significantly different from $d b / m$ treated with either MIg or mAb A717 $(P<0.05)$; * Significantly different from $d b / d b$ treated with MIg $(P<0.05)$. 

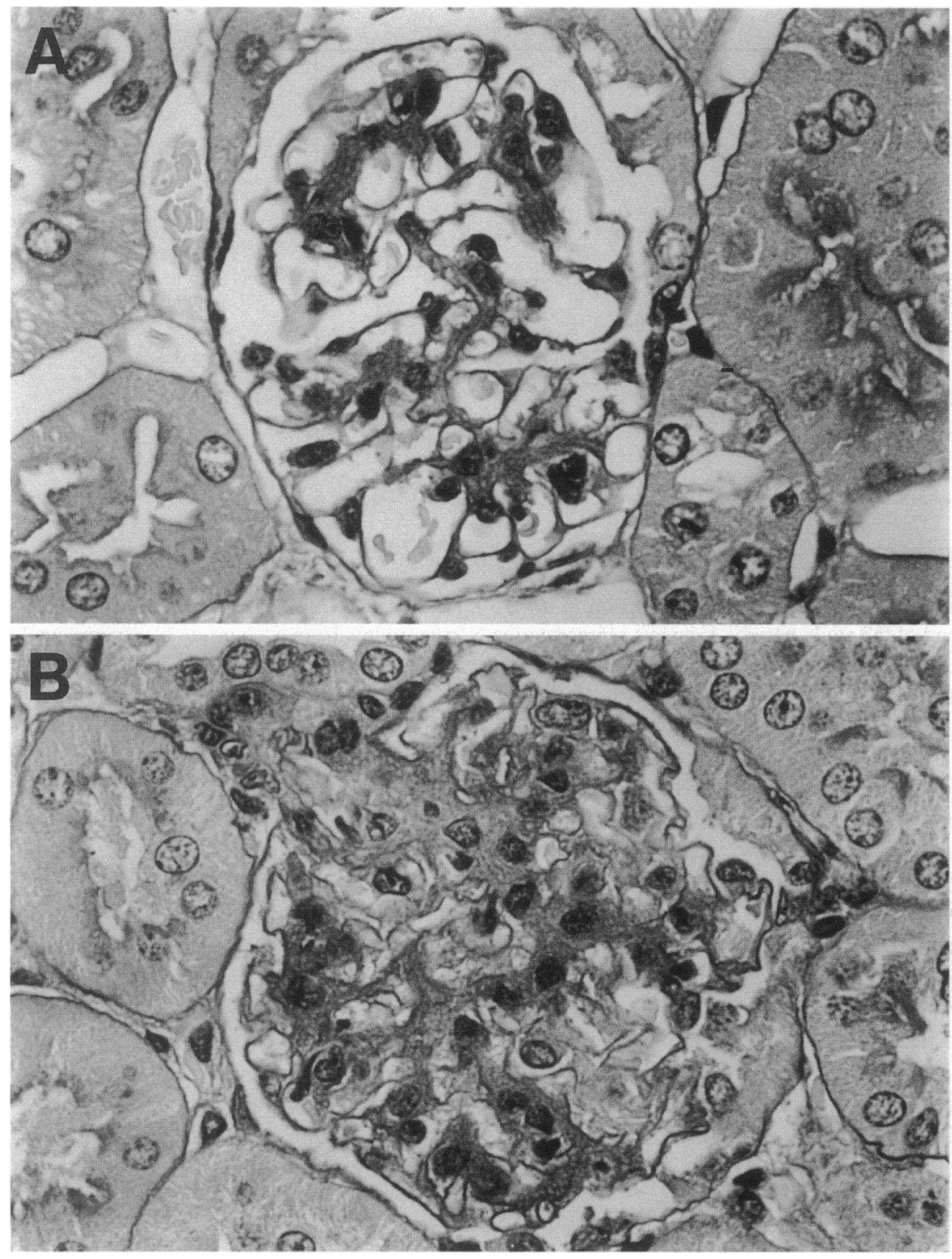

Figure 4. Prevention of glomerular pathology in $d b / d b$ mice by mAb A717. $d b / d b$ mice and their nondiabetic $\mathrm{db} / \mathrm{m}$ littermates were treated according to the legend to Fig. 1. Portions of the renal cortex were removed when animals were killed at the end of the study and frozen for histological examination. Sections were stained with PAS. (A) $d b / m$ MIg; (B) $d b / d b$ MIg; (C) $d b / d b \mathrm{~A} 717 ;(D)$ quantitation of extracellular matrix. Data are expressed as the fraction of total glomerular tuft cross-sectional area occupied by mesangial matrix. Results represent mean \pm SEM of 40-60 glomeruli in each animal group. *Significantly different from $\mathrm{db} / \mathrm{m}$ specimens $(P<$ $0.002) ; * *$ significantly different from $d b / d b$ MIg $(P<0.002)$. dure. Relative concentration of antibody ( $\mu \mathrm{g} / \mathrm{mg}$ protein) in renal cortex progressively diminished during the 48-h postinjection period studied, although the rate of decline in relative concentration tapered between 24 and $48 \mathrm{~h}$.

\section{Discussion}

We have shown that treatment of diabetic $d b / d b$ mice with a monoclonal antibody directed against glycated albumin prevents abnormalities in renal glomerular function, histopathology, and cell biology that are characteristic of the nephropathic lesion in diabetes. The quantitative analysis performed in the present experiments documents a nearly fourfold increase in mesangial matrix area in the $d b / d b$ mouse by age $16 \mathrm{wk}$. This was accompanied by a 2.6 -fold increase in collagen IV mRNA and a 3.8-fold increase in fibronectin mRNA in the renal cortex. Mesangial matrix fraction was significantly reduced, in association with marked attenuation in collagen IV and fibronectin mRNA levels, by treatment with A717 monoclonal antibodies, but not by treatment with IgG unreactive with glycated albumin. We interpret the amelioration of mesangial matrix expansion by $\mathrm{A} 717$ administration as a reflection of the decrease in overexpression of the type IV collagen and fibronectin genes, which is presumed to occur in the glomerulus and possibly in the tubulointerstitium (39-41). The starting material for mRNA extraction in these experiments was renal cortex, which contains proximal tubules as well as glomeruli. The tubulointerstitium in diabetes exhibits changes parallel to those found in the glomerulus, with increased basement membrane and overproduction of extracellular matrix (39-41). Notably, we did not treat the $d b / d b$ mice with insulin or other glucose-lowering agent, and blood glucose concentrations at the conclusion of the study were as elevated as they were at the initiation of the study period. Thus, treatment with the A717 monoclonal antibodies reduced urinary albumin excretion, prevented mesangial matrix accumulation, and attenuated the overexpression of renal matrix mRNA levels without any change in glycemic status. Hyperglycemia is the driving force for increased nonenzymatic glycation, 


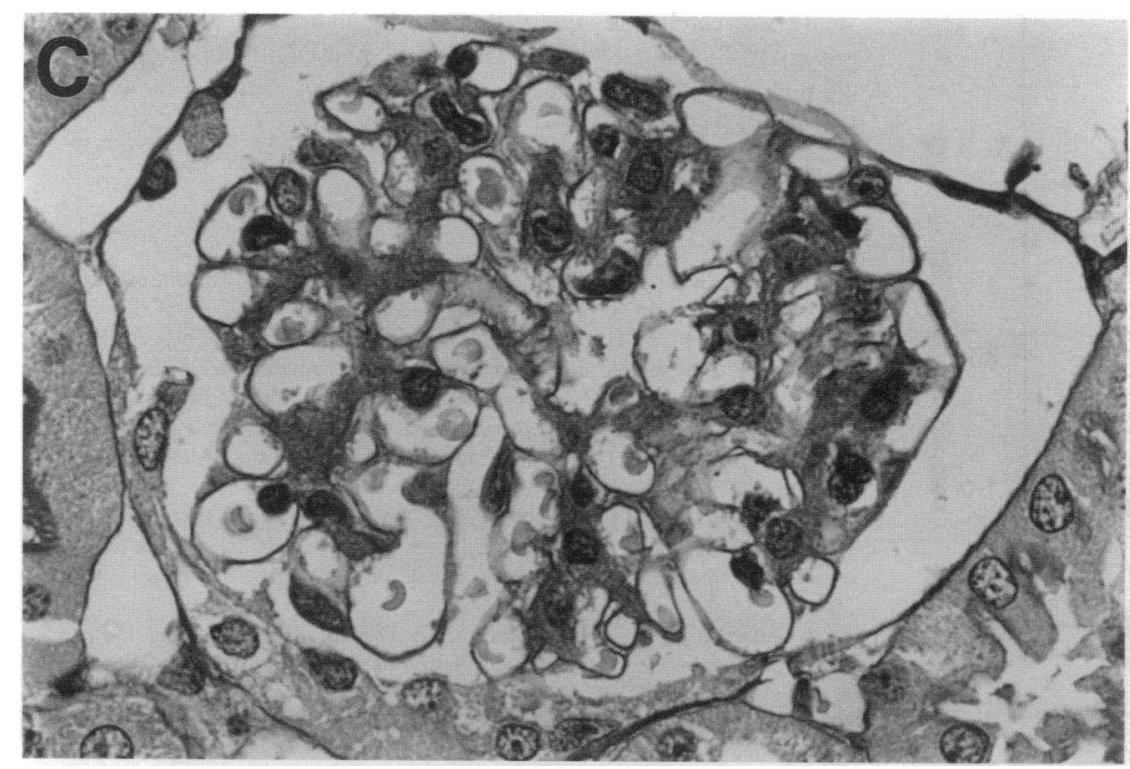

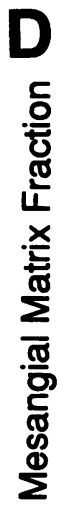

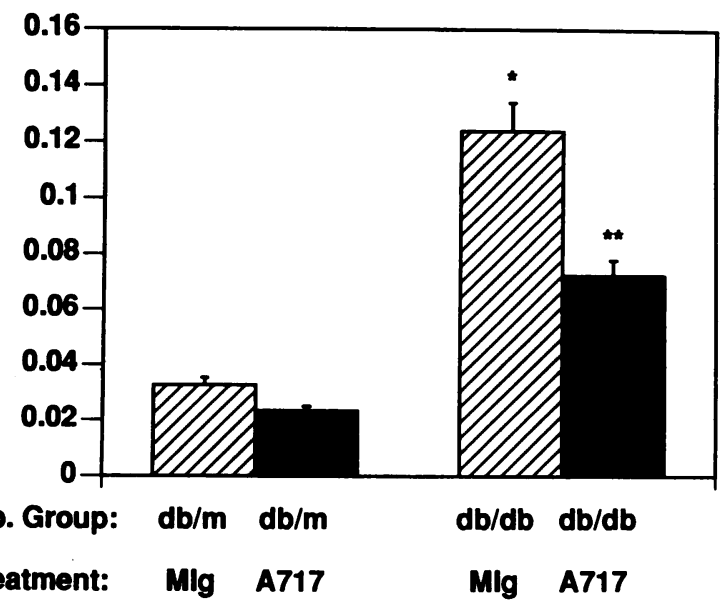

Figure 4 (Continued)

but, as these results indicate, the nephropathogenetic effects of increased glycated albumin in vivo can be corrected independent of antihyperglycemic therapy.

The lesion of diabetic nephropathy likely originates in the glomerular mesangium, which, in diabetes, is bathed with serum containing increased concentrations of glycated albumin. Our previous in vitro studies have shown that glycated albumin inhibits cellular replication and stimulates type IV collagen production by mesangial cells in culture, and that A717, but not IgG unreactive with glycated albumin, can prevent these effects $(14,19)$. The glycated serum and glycated albumin-induced changes in proliferation, collagen secretion, and collagen gene expression are observed with physiologic glucose concentration and are exaggerated in elevated glucose concentration (14). These findings are relevant to the in vivo situation, in which there are periods of normoglycemia and hyperglycemia, and suggest that the deleterious effects of glycated albumin on mesangial cell biology pertain regardless of glycemic fluctuations but are accentuated with hyperglycemic excursions.

The present experiments confirm that increased glycated albumin in diabetes is a potent stimulus in vivo of renal type
IV collagen and fibronectin gene expression, and they establish excess circulating glycated albumin as a target for therapeutic intervention in diabetic nephropathy. Elevated plasma glycated albumin concentrations in $d b / d b$ mice were significantly decreased when assayed $48 \mathrm{~h}$ after A717 administration (21), suggesting that the nephropathic protective effect of A717 treatment is consequent to a reduction in circulating biologically active epitopes. It is assumed that parenteral administration of A717 Fab fragments results in transient peaks, during which the complementarity-determining region rapidly binds to glycated albumin, promoting accelerated clearance by reticuloendothelial systems. Binding of A717 to the glycated albumin epitope may also block its ability to interact with cell membrane-associated polypeptides that may trigger receptor-induced intracellular events. The identification of selective binding proteins and cellular ligand receptor systems for Amadori-modified albumin and the demonstration that the A717 monoclonal antibody inhibits binding of glycated albumin to these receptor polypeptides support this hypothesis $(42-45)$. Blockade of the glycated albumin epitope by binding to antibody most likely occurs in the circulation, where it is readily accessible, inclusive of distal compart- 


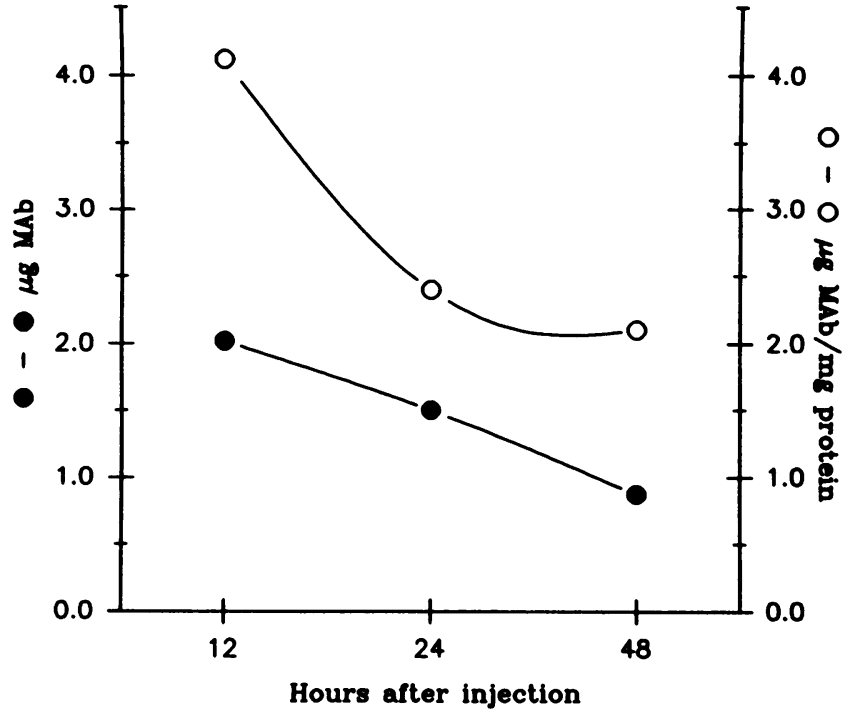

Figure 5. Appearance of A717 monoclonal antibody in murine renal cortex. $200 \mu \mathrm{g}$ of Fab fragments was injected intravenously into BALB/ $c$ mice, from which renal cortex was harvested at the indicated times after injection. Immunoanalysis for A717 was performed as described in the text. Results represent mean of two animals at each time period.

ments in proximity to cellular sites, particularly the serumbathed glomerular mesangium. As shown in these experiments, A717 antibody is detectable ( $1-4 \mu \mathrm{g} / \mathrm{mg}$ protein) in renal cortex obtained from normal mice $12-48 \mathrm{~h}$ after intravenous injection of $200 \mu \mathrm{g}$ of A717 Fab fragments.

Diabetic nephropathy is the single largest cause of end-stage renal disease in the Western Hemisphere and develops in 20$40 \%$ of patients with insulin-dependent diabetes and in many with non-insulin-dependent diabetes (46-49). Effective medical therapy to halt the inexorable progression of renal disease due to diabetes, once the process is initiated, has been elusive. The results of the Diabetes Control and Complications Trial have established that intensive regimens for blood glucose control can lower the risk for diabetic nephropathy and retinopathy (50). However, it is widely appreciated that implementation and maintenance of such regimens is difficult and may be risky, and that good control is not achieved in the majority of diabetic patients. For this reason, considerable effort has been directed at identifying intervention strategies that abrogate the deleterious effects of factors that act in concert with or independent of glycemic status in the pathogenesis of diabetic nephropathy. Use of angiotensin-converting enzyme inhibitors is one such strategy that has proved efficacious in arresting the decline in renal function, presumably on the basis of interruption of deleterious hemodynamic influences (51). Other potential points of intervention include inhibition of the polyol pathway and prevention of advanced glycation end product cross-link formation $(8,52,53)$. The present findings provide direct evidence that blocking the biologic effects of excess Amadori-glycated albumin in diabetes has a salutary influence on the development of diabetic nephropathy and suggest a new approach for the treatment of this morbid complication of diabetes.

\section{Acknowledgments}

We thank Dr. Eric G. Neilson (Renal Division, University of Pennsylvania) for critical reading of this manuscript.
This research was supported in part by National Institutes of Health grants DK-38308, DK-45191, DK-44513, and DK-07006. K. Sharma is the recipient of a National Research Service Award from the National Institutes of Health.

\section{References}

1. Koenig, R. J., S. H. Blobstein, and A. Cerami. 1972. Structure of carbohydrate and hemoglobin A. J. Biol. Chem. 252:2992-2997.

2. Bunn, H. F., K. H. Gabbay, and P. M. Gallop. 1978. The glycosylation of hemoglobin: relevance to diabetes mellitus. Science (Wash. DC). 20:21-27.

3. Higgins, P. J., and H. F. Bunn. 1987. Kinetic analysis of the nonenzymatic glycosylation of hemoglobin. J. Biol. Chem. 256:5204-5208.

4. Cohen, M. P. 1986. Diabetes and Protein Glycosylation: Measurement and Biologic Relevance. Springer-Verlag New York Inc.

5. Day, J. F., C. G. Ingelbretsen, W. R. Ingelbretsen, J. W. Baynes, and S. R. Thorpe. 1980. Nonenzymatic glycosylation of serum proteins and hemoglobin: response to changes in blood glucose levels in diabetic rats. Diabetes. 29:524527.

6. Guthrow, C. E., M. A. Morris, J. F. Day, S. R. Thorpe, and J. Baynes. 1979. Enhanced nonenzymatic glucosylation of serum albumin in diabetes mellitus. Proc. Natl. Acad. Sci. USA. 76:4258-4261.

7. Cohen, M. P., and E. Hud. 1989. Measurement of plasma glycoalbumin levels with a monoclonal antibody based ELISA. J. Immunol. Methods. 122:279283.

8. Brownlee, M., A. Cerami, and H. Vlassara. 1988. Advanced glycosylation end products in tissues and the biochemical basis of diabetic complications. $N$. Engl. J. Med. 318:1315-1321.

9. Makita, Z., H. Vlassara, A. Cerami, and R. Bucala. 1992. Immunohistochemical detection of advanced glycation end products in vivo. J. Biol. Chem. 267:5133-5138.

10. Aggarwal, M., and B. S. Daniels. 1992. Increased uptake of glycated albumin by glomerular mesangial and epithelial cells in situ is accompanied by augmented local production of $\mathrm{H}_{2} \mathrm{O}_{2}$. Clin. Res. 40:179a. (Abstr.)

11. Daniels, B. S., R. C. Brandt, and M. Aggarwal. 1993. Increased glomerular $\mathrm{H}_{2} \mathrm{O}_{2}$ production in diabetes: role of glycated proteins. J. Am. Soc. Nephrol. 4:791a. (Abstr.)

12. McVerry, B. A., A. Hopp, C. Fisher, and E. R. Huehns. 1980. Production of pseudodiabetic renal glomerular changes in mice after repeated injections of glycosylated proteins. Lancet. ii:738-740.

13. Sabbatini, M., G. Sansone, F. Uccello, A. Giliberti, G. Conte, and V. E. Andreucci. 1992. Early glycosylation products induce glomerular hyperfiltration in normal rats. Kidney Int. 42:875-881.

14. Cohen, M. P., and F. N. Ziyadeh. 1994. Amadori glucose adducts modulate mesangial cell growth and collagen gene expression. Kidney Int. 45:475-484.

15. Abrass, C. K., C. V. Peterson, and G. S. Raugi. 1988. Phenotypic expression of collagen types in mesangial matrix of diabetic and nondiabetic rats. Diabe tes. 37:1695-1702.

16. Osterby, R., H.-H. Parving, E. Hommel, H. E. Jorgensen, and H. Lokkegard. 1990. Glomerular structure and function in diabetic nephropathy: early to advanced stages. Diabetes. 39:1057-1063.

17. Mauer, S. M., M. W. Steffes, E. N. Ellis, D. E. R. Sutherland, D. M. Brown, and F. C. Goetz. 1984. Structural-functional relationships in diabetic nephropathy. J. Clin. Invest. 74:1143-1155.

18. Steffes, M. W., R. W. Bilous, D. E. R. Sutherland, and S. M. Mauer. 1992. Cell and matrix components of the glomerular mesangium in Type I diabetes. Diabetes. 41:679-688.

19. Ziyadeh, F. N., and M. P. Cohen. 1993. Effects of glycated albumin on mesangial cells: evidence for a role in diabetic nephropathy. Mol. Cell. Biochem. 125:19-25.

20. Cohen, M. P., and E. Hud. 1989. Production and characterization of monoclonal antibodies against human glycoalbumin. J. Immunol. Methods. 117:121-129.

21. Cohen, M. P., E. Hud, and V. Y. Wu. 1994. Amelioration of diabetic nephropathy by treatment with monoclonal antibodies against glycated albumin. Kidney Int. 45:1673-1679.

22. Like, A. A., R. L. Lavine, P. L. Poffenbarger, and W. L. Chick. 1972. Studies in the diabetic mutant mouse. Am. J. Pathol. 66:193-204.

23. Lee, S. M., and A. Graham. 1980. Early immunopathologic events in experimental diabetic nephropathy: a study in $d b / d b$ mice. Exp. Mol. Pathol. 33:323-332.

24. Lee, S. M., and R. Bressler. 1981. Prevention of diabetic nephropathy by diet control in the $d b / d b$ mouse. Diabetes. 30:106-111.

25. Durie, F. H., R. A. Fava, T. M. Foy, A. Aruffo, J. A. Ledbetter, and R. J. Noelle. 1993. Prevention of collagen-induced arthritis with an antibody to gp 39, the ligand for CD 40. Science (Wash. DC). 261:1328-1330.

26. Shima, K., K. Shi, Y. Noma, C. Yamamoto, and K. Yasukawa. 1991. 
High performance liquid chromatographic assay of rat serum glycated albumin. Diabetes. 40:205a. (Abstr.)

27. Rendell, M., P. M. Stephen, R. Paulsen, J. L. Valentine, K. Rasbold, T. Hestorff, S. Eastberg, and D. C. Shint. 1985. An interspecies comparison of normal levels of glycosylated hemoglobin and glycosylated albumin. Comp. Biochem. Physiol. 81B:819-822.

28. Kesaniemi, Y. A., J. L. Witztum, and U. P. Steinbrecher. 1983. Receptormediated catabolism of low density lipoprotein in man. Quantitation using glucosylated low density lipoprotein. J. Clin. Invest. 71:950-959.

29. Steinbrecher, U. P., and J. L. Witztum. 1984. Glycosylation of low density lipoproteins to an extent comparable to that seen in diabetes slows their catabolism. Diabetes. 33:130-134.

30. Wiklund, O., J. L. Witztum, T. E. Carew, R. C. Pitman, R. Elam, and D. Steinberg. 1987. Turnover and tissue sites of degradation of glucosylated low density lipoprotein in normal and immunized rabbits. J. Lipid Res. 28:10981109.

31. Hatton, M. W., M. Richardson, and P. D. Winocur. 1993. On glucose transport and nonenzymatic glycation of proteins in vivo. J. Theor. Biol. 161:481490.

32. Neuman, R. G., E. Hud, and M. P. Cohen. 1994. Glycated albumin: a marker for glycemic status in rats with experimental diabetes. Lab. Anim. 28:6369.

33. Ziyadeh, F. N., E. R. Snipes, M. Watanabe, R. J. Alvarez, S. Goldfarb, and T. P. Haverty. 1990. High glucose induces cell hypertrophy and stimulates collagen gene expression in proximal tubule. Am. J. Physiol. 259:F704-714.

34. Seyer-Hansen, K., J. Hansen, and H. J. G. Gunderson. 1980. Renal hypertrophy in experimental diabetes. A morphometric study. Diabetologia. 18:501505 .

35. Mogensen, C. E. 1990 . Prediction of clinical diabetic nephropathy in IDDM patients: alternatives to microalbuminuria. Diabetes. 39:761-767.

36. Ledbetter, S., E. J. Copeland, D. Noonan, G. Vogeli, and J. R. Hassell. 1990. Altered steady state mRNA levels of basement membrane proteins in diabetic mouse kidneys and thromboxane synthesis inhibition. Diabetes. 39:196203.

37. Ihm, C. G., G. S. L. Lee, C. C. Nast, R. Artishevsky, R. Guillermo, R. J. Levin, R. J. Glassock, and S. G. Adler. 1992. Early increased renal procollagen $\alpha 1$ (IV) mRNA levels in streptozotocin diabetes. Kidney Int. 41:768-777.

38. Fukui, M., T. Nakamura, I. Ebihara, I. Shirato, Y. Tomino, and H. Koide. 1992. ECM gene expression and its modulation by insulin in diabetic rats. Diabetes. 41:1520-1527.
39. Lane, P. H., M. W. Steffes, P. Fioretto, and S. M. Mauer. 1993. Renal interstitial expansion in insulin-dependent diabetes mellitus. Kidney Int. 43:661667

40. Ziyadeh, F. N. 1993. Renal tubular basement membrane and collagen Type IV in diabetes mellitus. Kidney Int. 43:114-120.

41. Ziyadeh, F. N. 1993. The extracellular matrix in diabetic nephropathy. Am. J. Kidney Dis. 22:736-744.

42. Predescu, D., M. Simionescu, N. Simionescu, and G. E. Palade. 1988. Binding and transcytosis of glycoalbumin by the microvascular endothelium of the murine myocardium: evidence that glycoalbumin behaves as a bifunctional ligand. J. Cell Biol. 107:1729-1738.

43. Wu, V. Y., and M. P. Cohen. 1993. Identification of aortic endothelial cell binding proteins for Amadori adducts in glycated albumin. Biochem. Biophys. Res. Commun. 193:1131-1136.

44. Krantz, S., R. Brandt, and B. Gromoll. 1993. Binding sites for short-term glycated albumin on peritoneal cells of the rat. Biochim. Biophys. Acta. 1177:1524.

45. Wu, V. Y., and M. P. Cohen. 1994. Receptors specific for Amadorimodified glycated albumin on murine endothelial cells. Biochem. Biophys. Res. Commun. 198:734-739.

46. Friedman, E. A. 1982. Diabetic nephropathy: strategies in prevention and management. Kidney Int. 21:730-738.

47. Mogensen, C. E. 1984. Microalbuminuria predicts clinical proteinuria and early mortality in maturity-onset diabetes. $N$. Engl. J. Med. 310:356-360.

48. Noth, R. H. 1989. Diabetic nephropathy: hemodynamic basis and implications for disease management. Ann. Intern. Med. 110:795-813.

49. Andersen, A. R., J. S. Christiansen, and J. K. Andersen. 1983. Diabetic nephropathy in Type I (insulin-dependent) diabetes: an epidemiological study. Diabetologia. 25:496-501.

50. The DCCT Research Group. 1993. The effect of intensive treatment of diabetes on the development and progression of long-term complications of insulin-dependent diabetes mellitus. N. Engl. J. Med. 329:977-986.

51. Lewis, E. J., L. G. Hunsicker, R. P. Bain, and R. D. Rohde. 1993. A clinical trial of angiotensin converting enzyme inhibitor in the nephropathy of insulin-dependent diabetes. N. Engl. J. Med. 329:1456-1463.

52. Winegrad, A. I. 1987. Does a common mechanism induce the diverse complications of diabetes? Diabetes. 36:396-406.

53. Brownlee, M., H. Vlassara, A. Kooney, P. Ulrich, and A. Cerami. 1986. Aminoguanidine prevents diabetes-induced arterial wall protein cross-linking. Science (Wash. DC). 232:1629-1632. 